\title{
Implementation of Online Reverse Auctions: Comparison of Czech and Slovak Construction Industry
}

\author{
Tomas Hanak ${ }^{1}$ Tomas Chadima ${ }^{2}$, Jana Selih ${ }^{3}$ \\ ${ }^{1,2}$ Brno University of Technology \\ Veveri 95, 60200 Brno, Czech Republic \\ E-mail.hanak.t@fce.vutbr.cz,chadimat@study.fce.vutbr.cz
}

${ }^{3}$ University of Ljubljana

Jamova cesta 2, p. 3422, 1001, Ljubljana, Slovenia

E-mail.jana.selih@fgg.uni-lj.si

cross $^{\text {ref }}$ http://dx.doi.org/10.5755/j01.ee.28.3.12505

Online Reverse Auctions (ORA) are an electronic commerce tool that enables direct communication between buyers and sellers and thus have the potential to make the procurement processes more efficient which leads to improved business performance of the buyer. The presented research investigates how ORA are implemented in the specific environment of Czech and Slovak construction industry. The barriers and drivers associated with this procurement route were identified by investigating the available body of literature. Next, an empirical study investigating the use of ORA was conducted within Czech and Slovak construction industry using a carefully designed online survey.

The results show that there is a difference between the adoption levels of ORA between the Czech Republic and Slovakia. Decrease in bid prices and increased transparency are perceived as the most important drivers for ORA users while unwillingness of suppliers to participate, followed by high acquisition costs are perceived as the most important barriers. The identified importance of drivers and barriers of the ORA use provides the starting point for the implementation of this procurement route in construction industry, which will lead to increased competitiveness of the sector in the next step. The obtained results confirm that this procurement route has a significant potential within the construction industry.

Keywords: Construction Industry, Cost Management, Online Reverse Auction, Purchasing Management, Survey.

\section{Introduction}

The current business environment requires permanent improvement of operations in any enterprise. Within this context, purchasing management is one of the key processes within any enterprise where improvements can be made. As purchasing departments in organizations play a critical role in relation to productivity and innovation (Ubeda et al., 2015), the improvement of procurement management should be considered a strategic priority (Presutti, 2003) leading to rationalization of the use of employees' working time, and can thus have an impact upon the productivity, business efficiency and performance of the company as a whole.

Due to continuously decreasing costs of IT tools, enterprises are increasingly adopting contemporary eprocurement tools (Smart, 2010; Toktas-Palut et al., 2014). Several electronic commerce technology options are available today. One of them is Online Reverse Auction (ORA), where sellers bid for the prices at which they are willing to sell their goods and services, as opposed to a regular auction where buyers place bids (Standing et al., 2013). This tool can be used in different ways and can be applied to the majority of industrial sectors.

From the viewpoint of the buyer, two things are needed for an efficient use of ORA: to be able to precisely describe the product in demand and to define and quantify the selection criteria. If the product cannot be described at the time of purchase, alternative procurement routes, such as Competitive Dialogue should be used.

Implementation of ORA is an innovation that may be particularly important for institutions that need to purchase various products and services on a daily basis. Most construction contracting companies operate in this way. Nevertheless, these companies are often conservative in their business attitudes and consequently they implement the contemporary IT technology at a slow pace (Bygballe \& Ingemansson, 2014). It is therefore possible that the implementation of ORA in construction companies is faced with challenges that are not encountered in other industrial sectors.

\section{Research problem}

Implementation of ORA can be considered a technological as well as an organizational innovation, therefore its use can have a significant beneficial impact upon the business performance of the client organisations; however data related to the actual implementation of ORA in specific countries is lacking. In particular, this invaluable knowledge is missing for the transition countries that underwent large sociopolitical changes in the recent past, and they could use it for more successful implementation of this procurement route in practice.

Objectives. The first objective of the present research is to identify the key barriers and drivers that influence the 
adoption of ORA, along with their perceived importance. The second objective is to assess the use of this procurement route within the construction industry in the Czech Republic and in Slovakia in both qualitative and quantitative terms. There are certain similarities between these two countries due to their historical development, even though they currently face different socioeconomic challenges (see e.g. Cechura \& Mala, 2014; Filer et al., 1999; Stritesky, 2014). A study of the implementation of this particular procurement route that takes into account both countries will also yield an insight into the business trends in construction sector in this part of Central Europe.

\section{Literature Review}

Early research (Bartels et al., 2003) reports that 7 out of 10 US companies use e-procurement to obtain strategic items. In Austrian construction industry, $64 \%$ of respondents use some kind of e-procurement system (Zung et al., 2014). Purchase and Dooley (1010), who studied the e-procurement routes, found that online catalogues are the most commonly used method of e-procurement $(57.4 \%)$, but $12.6 \%$ of respondents stated that they also use online reverse auctions.

The latter procurement route (named also downward price auctions) has become a popular method for decreasing the purchase price of durables over the past decade, most often used by large companies (Emiliani \& Stec, 2002). The purchasing organization demands a product or a service (in other words, offers a contract) and the contenders lower their prices in order to win the contract (Smart, 2010; Carter et al., 2004). The method has been popular from the very beginning, mostly due to its simple functionality, userfriendly interface and several accompanying benefits. Some authors consider ORA the most successful business model in the electronic marketplace (Dashnyam et al., 2012) that serves as a new form of transaction introducing variability into many aspects of a commercial exchange (Walley \& Fortin, 2005). From the financial perspective, in the private sector, ORA therefore contributes by purchasing price reductions to the increased profitability, which is, e.g. for the building construction companies, the most significant performance indicator (Ali et al., 2013).

The use of ORA eliminates the influence of the human factor over the buying process and therefore its use in practice evokes certain ethical questions (Carter et al., 2004).

The decrease in bid prices during online price negotiations is the main benefit of the use of ORA. Several factors influence this process. The most important ones are the type of product in demand, the competition and the number of contenders (Ray et al., 2011; Carter et al., 2004; Emiliani, 2000). The process is also influenced by the attractiveness of the demanded volume, the prestige of the buyer and the ratio between supply and demand. Furthermore, the decrease in bid prices is also influenced by the level of competition among the suppliers (Carter et al., 2004). Generally, the savings gained in this way range between 5 and $40 \%$ (Hawkins et al., 2010; Foroughi et al., 2007). Existing research (Schoenherr \& Mabert, 2007) also shows that smaller firms tend to lag in terms of online auction adoption when compared to larger- and mediumsized enteprises.
Different areas of production and provision of services (Smart, 2010) exhibit different levels of the use of online auctions. Similarly, the nature of the examined industrial sector seems to influence the amount of research conducted in the area of ORA use. The conducted literature review reveals that research dealing with application of ORA in the field of construction industry is scarce; one of the few works found during the literature search is Hatipkarasulu \& Gill (2004). Research focusing on the implementation of ORA in the construction sector is therefore highly relevant, as it may result in facilitating more efficient procurement routes.

\section{Identification of Reasons for Adopting of ORA}

Implementation of ORA presents an interesting possibility to achieve a number of benefits. From the buyer's perspective, ORA promote greater efficiency of the purchasing process (Aloini et al., 2012), especially achieving a decrease in bid price and purchase time reductions. Decrease in bid prices can be considered the primary factor, as is apparent in the majority of research studies on ORA, e.g. (Wagner \& Schwab, 2004), and in the case of construction contributes to better net cash flows of investments (Korytarova \& Pospisilova, 2015). However, savings potential advertised by the ORA operator can only be viewed as gross savings. Comprehensive evaluation should include associated costs and losses, such as implementation costs, switching costs or higher transportation costs (Emiliani $\&$ Stec, 2002), incurred e.g. due to the distance between the supplier and the construction site, that may be large in the construction practice (Jaskowski et al., 2014). Such evaluation may be difficult, since organizations report difficulties in cost assessment (William \& Hardy, 2007).

Purchase time reductions are another often-cited benefit in the scientific literature. The potential for achieving time savings depends on the nature of the demanded commodity: higher savings can be anticipated for less complex commodities (Emiliani, 2000) and vice versa. In addition, time reduction may be dependent on the type of buying situation (Abu-El Samen et al., 2010). More significant reductions are related mostly to straight rebuy in contrast with new task, since ORA makes it possible to automate the purchasing process for repeated purchases. It should be noted, however, that such situations are mainly applicable to mass industrial production, rather than to the projectbased construction industry.

The ORA system records all operations that are carried out in the tender, and provides monitoring access to the auction house for the management of the buying institutions or for institutions otherwise involved in the process (e.g. banks or other funding institutions). This enhanced transparency of the purchasing process (Yu et al., 2007) could be of particular interest to both public authorities and private investors primarily in countries where the level of corruption in the construction sector is high. The typical construction process consists of a series of demanding tasks and activities throughout the entire project

life cycle, which contributes to the occurrence of corruption activities during all project phases (Nordin et al., 2011). For example, Report Exploring Corruption in the UK Construction Industry states that $43 \%$ of the respondents, who are professionally engaged in construction, feel that 
corruption can occur at all stages of the construction process (pre-qualification and tendering phase were recognized as the ones most susceptible to corruption) (The Chartered Institute of Building, 2013).

The above-mentioned benefits could be considered as having the largest influence upon the decision regarding ORA adoption. In addition, auctions also support the elimination of spatial, geographical and language barriers (Walley \& Fortin, 2005) and allow easy benchmarking (Pearcy et al., 2007). The suppliers are also given the opportunity to make bids in real time, thus particular benefits can be identified on both supply and demand sides.

\section{Identification of Barriers for Adopting ORA}

The type of product in demand may considerably influence the suitability of ORA application. For example, Foroughi et al. (2007) concludes that standardized products are more appropriate, but even complex products can be auctioned successfully. In order to arrive at the final deal, it is essential that the investor is able to specify the key characteristics of the product - physical characteristics, quality and location requirements, frequency of the service, etc. (Hawkins et al., 2010).

Nevertheless, ORA cannot replace traditional methods of price determination for every product or service, especially if the product or service cannot be clearly specified beforehand (Caniëls, \& van Raaij, 2009). In the construction field, for example, this is the case of architectural and structural design. In these cases, other methods of procurement should be considered, as they are more appropriate. Some buyers are concerned about the unwillingness of suppliers to participate in ORA (Lösch \& Lambert, 2007). If the environment is competitive, however, it can be expected that there will always be a sufficient number of companies who are willing to participate. Resistance to ORA may be based on the opinion that face-toface negotiations are the most important means of conducting procurement activities, and that ORA cannot support the formation of collaborative long-term relationships (Hartley et al., 2004; Tassabehji, 2010).

Evaluation of auction events should include all costs associated with the acquisition of ORA system, i.e. total costs of ownership (Aloini et al., 2012). In order to use this auction type, the company can create its own program, buy a standardized SW solution or hire an existing system. It should be noted, however, that the first two opportunities are associated with relatively high acquisition costs that may hinder the implementation of ORA.

The buyers often claim that they give preference to quality over price. This can be resolved by providing comprehensive, unambiguous tender documentation, so that the supplier fully understands the customer's purchasing requirements, including the quality standards (Hawkins et al., 2010). The product should be described by relevant quantifiable parameters, such as load capacity, thermal permeability or door dimensions.

General barriers related to the adoption of ICT in construction sector may also play a role, such as absence of required skills or prevailing traditions and culture (Vitkauskaite \& Gatautis, 2008).
As in the case of benefits, important barriers may also occur on both sides (buyers' and suppliers'). Other possible barriers that may prevent ORA adoption are lack of eauction knowledge (Hartley et al., 2006), concerns about distortion of customer-supplier relationships, requirements related to HW and SW equipment, presence of a monopoly and insufficient IT personnel on the supplier's side.

\section{Methodology}

Systematic review of literature was employed as the research method for achieving the first objective. The second objective was obtained by carrying out an online survey in both examined countries. The survey was distributed to a set of various stakeholders in the construction industry in order to obtain a qualitative and quantitative assessment of their viewpoints and the use of ORA, and, on this basis, to test the hypotheses. The survey was carried out from 2013 to 2014.

The study population consisted of subjects operating in the Czech and Slovak construction sector, both on the client and on the supplier side. Because construction projects involve a large number of stakeholders, the study population has been thoroughly designed with a view to cover clients, general contractors, subcontractors and design and consulting engineering companies.

The content of the web-based questionnaire used in the survey was systematically justified on the basis of the literature review that had been performed, the list of identified drivers and barriers affecting the ORA implementation in the construction industry and the established hypotheses. The first part was aimed at obtaining general data about the respondents such as the role of the stakeholder in construction projects, position of the responding person within the institution or the size of the institution. In the second part, essential information regarding ORA use, frequency of use and roles of respondents in ORA was collected. Such data makes it possible to examine to what extent the role of the institution and its size influence the perception of ORA or the frequency of their use. It is also possible, for example, to determine the participation of public and private bodies in the client role of ORA.

The third part of the survey was designed to assess the perception of the key benefits and barriers significance by different project stakeholders and to determine to what extent they agreed with the statement that ORA help automate the purchasing process in the construction industry. Respondents were asked to assess the set of the questions/statements in the third section of the survey on a 5-point Likert scale where 1 indicates the most significant statement (strong agreement) and 5 indicates the least significant statement (strong disagreement).

\section{Research Hypotheses}

The primary aim of this study is to identify and compare the implementation of ORA in the Czech Republic and Slovakia in the construction field. The first hypothesis, H1, is therefore defined as follows:

H1: The rate of ORA adoption is dependent on the location (affiliation to the country). 
During the performed literature review, decrease in bid price and unsuitable type of product were identified as a significant benefit and barrier on the demand side, respectively. Accordingly, hypotheses $\mathrm{H} 2$ and $\mathrm{H} 3$ were formulated as follows:

$\mathrm{H} 2$ : Decrease in bid price is the most significant benefit perceived by clients in both the Czech Republic and Slovakia.

H3: Unwillingness of suppliers is the most significant barrier perceived by clients in both the Czech Republic and Slovakia.

Since private companies should be more concerned about distortion of customer-supplier relationships than public authorities, it can be expected that the client using ORA will be typically a public investor.

H4: Clients using ORA are predominantly public bodies.

Evaluation of hypothesis H1 is based on chi square test of independence allowing the determination of the association between categorical variables. In relation to hypotheses $\mathrm{H} 2$ and $\mathrm{H} 3$, ranking of the importance of individual parameters evaluated by respondents on the Likert scale is performed using relative importance index $(R I I)$ :

$$
\mathrm{RII}=\sum_{1}^{i=A} \frac{\mathrm{n}_{i} * \mathrm{i}}{A * N}
$$

where $n_{i}$ is the number of respondents who have assigned weight $i$ to the evaluated factor; $A$ is the highest possible rating of significance and $N$ is the total number of respondents.

\section{Results and Discussion \\ Description of Study Area}

The research reported in this paper compares the use of ORA in the Czech Republic and Slovakia, that is, the two independent countries that came into existence in 1993 as a result of the division of Czechoslovakia. Basic macroeconomic and other statistical indicators, such as GPD, population and average number of employees in construction sector are shown in Table 1 for the two countries under consideration.

Table 1

General characteristics of the Czech Republic and Slovakia (source of data: $\mathrm{CZSO}^{\mathrm{a})}$ and SOSR ${ }^{\mathrm{b})}$, MTCRD ${ }^{\mathrm{c}}$, data corresponds to 2014)

\begin{tabular}{|l|c|c|}
\hline \multicolumn{1}{|c|}{ Indicator } & Czech Republic $^{\text {a) }}$ & Slovakia \\
\hline Population (ths.) & 10,538 & $5,421^{\text {b) }}$ \\
\hline GDP total (mil. EUR) & $155,856^{*}$ & $75,561^{\text {b) }}$ \\
\hline $\begin{array}{l}\text { Share of construction on total GDP } \\
(\%)\end{array}$ & 4.8 & $7.5^{\text {c) }}$ \\
\hline Rate of unemployment (\%) & 5.8 & $13.2^{\text {b) }}$ \\
\hline $\begin{array}{l}\text { Average number of employees in the } \\
\text { construction sector (ths.) }\end{array}$ & 215 & $156.8^{\text {c) }}$ \\
\hline
\end{tabular}

*the value is converted from CZK to EUR using the official exchange rate of April 8, 2015 (1 EUR = 27.375 CZK).

a) $\mathrm{CZSO}=$ Czech Statistical Office

b) SOSR = Statistical Office of the Slovak Republic

c) MTCRD = Ministry of Transport, Construction and Regional Development of the Slovak Republic.
The data presented in Table 1 was obtained from the official databases of the Czech Statistical Office (CZSO) and Statistical Office of the Slovak Republic (SOSR). It can be observed that the population of Slovakia is about half that of the Czech Republic. In terms of total GDP, Slovakia amounts to around half of the GDP in the Czech Republic. The data also shows that the rate of unemployment in Slovakia is considerably higher.

In terms of the share of construction within the total GDP, construction sector contributes more significantly to the overall GDP in Slovakia $(7.5 \%)$ when compared to the Czech Republic (4.8\%). Correspondingly, the number of employees in the construction sector is slightly higher in Slovakia when compared to the total population. This observation can be explained by the fact that in the Czech Republic other industrial sectors (e.g. automotive industry, engineering industry) forms higher GDP proportion then in Slovakia.

\section{Respondents to the Survey}

More than 2,000 institutions were invited electronically to share their experience and/or attitude to ORA. The participation was voluntary and completely anonymous. In total, 236 respondents have completed the survey. Respondents from the Czech Republic and Slovakia constitute $43 \%$ and $57 \%$ of the research sample, respectively. The sample size as well as the distribution of respondents with regard to their location allows relevant comparison of collected data with the support of statistical techniques.

It was also found that the respondents who participated in the survey are in a position to give relevant answers to the survey questions, since they predominantly act as members of management boards (62.3\%); purchasing personnel, project managers and "others" accounted for $14.8 \%, 11.0$ $\%$ and $11.9 \%$ of the sample, respectively. This confirmation is particularly important from the perspective of the subsequent evaluation of the significance of individual benefits and barriers.

\section{ORA Acceptance}

Acceptance rate of ORA shows differences between the two examined countries. Auctions are more often used in the Czech Republic than in Slovakia (see Table 2). Czech clients (predominantly public authorities) use ORA more frequently $(62 \%)$ than Slovakian clients $(33 \%)$. In the case of contractors, the frequency of use is considerably lower than in the case of clients; however, even in this case Czech companies are confronted with auctions more frequently than Slovakian companies.

We attribute this difference to the fact that since 2011, the use of ORA has been compulsory in Slovakia for specified types of public tenders (even though in the case of construction contracts, this obligation was not applied very strictly and its use is currently optional) and such regulation likely caused a negative perception of auctions for a certain part of the professional public because of their mandatory application even in less appropriate situations. 
Rate of ORA use

\begin{tabular}{|c|c|c|c|c|c|}
\hline \multirow[t]{2}{*}{ Role within ORA } & \multirow[t]{2}{*}{ Use of ORA } & \multicolumn{2}{|c|}{ Czech Republic } & \multicolumn{2}{|c|}{ Slovakia } \\
\hline & & No. of answers & $\%$ & No. of answers & $\%$ \\
\hline \multirow{3}{*}{ Client } & Yes & 31 & 62 & 19 & 33 \\
\hline & No & 19 & 38 & 39 & 67 \\
\hline & Total & 50 & 100 & 58 & 100 \\
\hline \multirow{3}{*}{ Contractor } & Yes & 16 & 31 & 17 & 22 \\
\hline & No & 36 & 69 & 59 & 78 \\
\hline & Total & 52 & 100 & 76 & 100 \\
\hline
\end{tabular}

The research has tested whether there is a statistically significant relationship between the use of ORA and the distribution of respondents between the two examined countries. Accordingly, two categorical variables have been defined: institutions located in the Czech Republic and institutions located in Slovakia. Out of 102 Czech institutions, 47 respondents reported the use of ORA in comparison to only 36 respondents out of 134 Slovakian institutions.

For chi-square test, the null hypothesis refers to the two categorical variables not being related. The alternative hypothesis then says that two categorical variables are dependent. Data were tested with a 5\% significance level.

For a chi square value of 9.376 with 1 d.f. (degree of freedom), $\mathrm{p}$-value $=0.002$. Because $\mathrm{p}<0.05$, there is enough evidence to reject the null hypothesis about the independence of examined variables and an alternative hypothesis should be accepted. Accordingly, hypothesis H1 was confirmed: the rate of ORA adoption is dependent on the location (affiliation to the country).

Current body of knowledge presents several drivers motivating clients to implement ORA as a part of their institutional purchasing strategy. This study explored the following 4 drivers that are been recognized as potentially the most influential: bid price decrement (BPD), enhanced transparency of purchasing process (ET), purchase time reductions (PTR) and elimination of language and geographical barriers (ELGB).

The examination of hypotheses $\mathrm{H} 2$ and $\mathrm{H} 3$ is performed using RII. For each driver and barrier, individual value of RII has been computed separately for Czech and Slovak respondent categories. The higher the value of RII, the more significantly the examined parameter is perceived by the respondents.

The evaluation of the significance of individual drivers by clients is shown in Figure 1. From the data presented in Figure 1 it can be noted that the perception of benefits by Czech (CZ) and Slovak (SK) institutions is similar. Although the benefits of bid price decrement and enhanced transparency clearly outweigh the two remaining ones, their ranking differs between two countries: in the Czech Republic, the most important benefit is the bid price decrement, while in Slovakia it is enhanced transparency. Based on this result, it seems likely that the Slovak construction sector faces a more significant challenge with regard to a lack of confidence in the fairness of tender procedures.

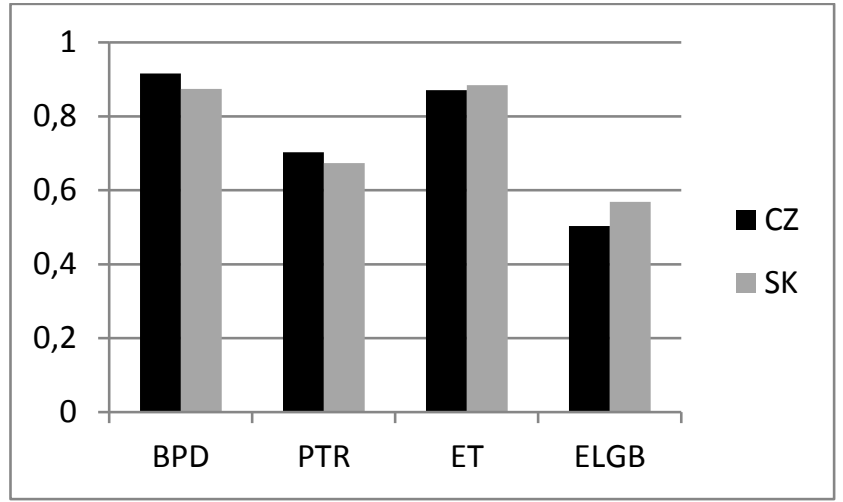

Figure 1. Importance of drivers in terms of RII

Hypothesis $\mathrm{H} 2$ states that decrease in bid price, an essential benefit of ORA, is perceived as the most significant among the 4 examined drivers in both the Czech Republic and Slovakia. Since in Slovakia, enhanced transparency has higher RII value than bid price decrement, hypothesis $\mathrm{H} 2$ was rejected.

Similarly to benefits, barriers were also subjected to evaluation in terms of their significance within ORA use. Specifically, it was investigated which of the following four barriers is perceived as the most significant by clients: unsuitable product (UP), unwillingness of suppliers to participate (USP), acquisition costs (AC) and concerns about the decline in quality (CDQ). The results of the comparison expressed in terms of RII are shown in Figure 2.

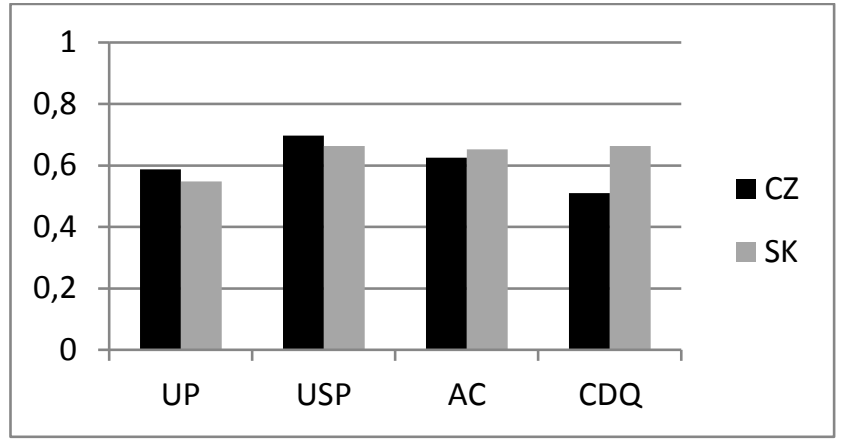

Figure 2. Importance of barriers in terms of RII

The most significant barrier related to the implementation of ORA in the construction sector is the unwillingness of suppliers to participate in auction. In the Czech Republic, this barrier clearly outweighs the other ones, while in Slovakia, concerns about the decline of quality of the works delivered has the same importance as the unwillingness of suppliers. In addition, acquisition costs are perceived to be almost as significant as the two above mentioned barriers. 
On the basis of this data, it can be argued that construction works cannot be considered unsuitable for ORA. On the other hand, unwillingness of suppliers to participate in tenders implemented using ORA seems to be crucial obstacle acting against wider application of auctions in practice. This unwillingness of contractors can be attributed to the dynamic real-time comparison of bid prices that forces bidders to significantly lower their bids in auctions, making the competitive pressure clearly higher than in "standard" tender procedures. Although some authors argue that ORA can contribute to increasing the number of suppliers (Tarazona-Bermudez et al., 2014; Standing et al., 2013), in the case of public works contracts, the effect of auctions is rather the opposite.

Surprisingly, a significant disparity of concerns about the decline in quality was evidenced between the examined countries. Explanation of this phenomenon, however, requires further detailed research examining quality standards and the level of supervision of the investor during the implementation of construction works.

Hypothesis H3 claimed that unwillingness of suppliers to participate in ORA is the most significant barrier perceived by clients in both Czech Republic and Slovakia. Based on the results, hypothesis $\mathrm{H} 3$ can be confirmed; nevertheless, it has to be noted that for Slovakia, concerns about the decline in quality have the same RII value as the examined parameter.

The last research hypothesis examined in this paper concerned the representation of public and private investors in the role of ORA client. Data relevant to hypothesis H4 are presented in the Table 3.

Table 3

Representation of public and private investors - ORA clients

\begin{tabular}{|l|c|c|}
\hline Type of investor & Czech Republic & Slovakia \\
\hline Public & 25 & 18 \\
\hline Private & 6 & 1 \\
\hline Total & 31 & 19 \\
\hline
\end{tabular}

The distribution of data does not allow applying a chi square test of independence, since frequency is less than 5 in more than $20 \%$ of cells in Table 3. Nevertheless, it is evident that in both countries, institutions acting as client in ORA are predominantly public authorities. Very sparse use of auctions for purchase by private companies is primarily the result of efforts to build good B2B relationships based on trust and experience (which is important e.g. when selecting a subcontractor). In addition, buyers must also take into account other relationship aspects, such as joint development projects or access to innovation (Charki et al., 2011). On the other hand, in the public sector the effect of relationships should play no role as supplier selection should be based purely on achieving maximum performance at the lowest cost.

\section{Discussion}

The main motivation to use ORA is closely related with the effort to decrease the award price in the tender and ensure the transparency of the tender procedure. This research finding, which is based on the results presented in Figure 1, corresponds with the statements published in other research studies (e.g. Hawking et al., 2010). This claim, however, contradicts Tassabehji's findings suggesting that the primary motivation for ORA use by procurement professionals to build relationships rather than to reduce bid prices (Tassebehji, 2010). This discrepancy can be explained by the fact that the majority of respondents in Tassabehji's research consisted of large multi-national organisations operating in heavy industry sectors (e.g. mining, oil, chemicals and manufacturing), while the presented study consists solely of construction industry representatives, regardless of the size of the institution and its affiliation to the public or private sector.

Building sustainable relations within ORA in construction sector is, by contrast, a big obstacle, as contractors are often reluctant to participate in the auction. This is due to very low margins resulting from participating in an auction with a highly competitive environment; as a consequence, contractors prefer traditional tenders. However, if the investor is able to create sufficient level of competition in the auction room despite the reluctance of some current contractors to participate, application of ORA will be definitely justified.

In Slovakia, enhanced transparency is perceived as the main driver and in the Czech Republic it is a very significant motivation for ORA use as well. Trustworthiness of the client and his way of contractor selection is of particular interest especially in countries where corruption is considered as a serious problem in the economy. From this perspective, both Czech and Slovakia countries face this phenomenon. According to the report on Businesses' Attitudes Towards Corruption in the EU (Flash Eurobarometer 374, 2014), corruption is predominantly perceived as a widespread problem in both the Czech Republic and Slovakia. A significant positive effect of enhanced transparency can be expected primarily in countries with a high level of corruption; in the context of EU, it applies not just to the Czech Republic and Slovakia, but also to Portugal, Greece, Romania, Cyprus or Hungary. In addition, the above mentioned report notes that construction companies are the most likely to say that corruption is widespread (Flash Eurobarometer 374, 2014); therefore, the application of ORA in the construction sector is highly in demand.

This research has shown that purchases related to construction industry cannot be considered as the crucial barrier for ORA adoption. In the case of Slovakia, they are even perceived as the least significant one from the evaluated list. However, the essential condition for successful application of ORA, the ability to specify demanded product in detailed and accurate way, must be satisfied.

Adoption of ORA in construction also suffers from concerns about the decline in quality. It is therefore crucial that ORA are applied primarily for such purchases where the subject of delivery can be well controlled and monitored during the execution of the delivery. Proper site monitoring is considered a fundamental activity contributing to the minimization of the rate of defects in construction projects (Leung et al, 2008) and requires timely collection and extensive analysis of data on construction processes (Liu et $a l$, 2015). From this viewpoint, the performance of construction works under technical supervision ensured by the investor seems to be appropriate situation for ORA; on 
the other hand, the delivery of project documentation or the purchase of products based primarily on the utilization of mental skills (consultancy etc.) seems to be considerably less relevant.

When comparing the Czech Republic and Slovakia, several similarities and differences have been revealed. Firstly, in both countries, drivers are perceived more significantly than barriers, hence the application of ORA is generally justified. Secondly, ORA are predominantly used by public authorities as clients, since the effect of relations between contracting parties is negligible in public works contracts.

Thirdly, when speaking about the disparities, ORA are more popular among Czech public authorities as demonstrated in terms of rate of use. Furthermore, if the drivers and barriers are examined in more detail, several other differences can be observed as well. First of all, the disparity in the perception of concerns about the decline in quality barrier should be further examined to explain why these concerns are stronger in Slovakia than in the Czech Republic. Another aspect worthy of further investigation is the potential extension of the use of ORA by private clients, which may to some extent be seen in the case of the Czech Republic.

Since contractors in the construction industry are predominantly selected by using the traditional form of the tender, the acceptance of ORA currently represents an important form of innovation of the purchasing process. The innovators are typically institutions with high levels of profitability (Horta et al., 2012), therefore the use of ORA may serve as an important tool for improving the business performance.

\section{Conclusion}

The objectives of this paper were to identify the perceived importance of the key barriers and drivers influencing ORA adoption and assess the use of this electronic procurement route within the Czech and Slovak construction industry.

The results show that, in many aspects, there are differences between the Czech Republic and Slovakia. Firstly, the rate of ORA adoption is dependent on the location, i.e. affiliation to the country. In particular, rate of
ORA use is higher in the Czech Republic than in Slovakia (according to the chi square test, the dependence of examined variables is statistically significant).

Secondly, there are no substantial differences in the perception of drivers; however, the order of individual benefits from the perspective of their significance varies between the two countries. Thirdly, larger differences were observed in the context of the perception of barriers, especially as regards the concerns about the decline in the quality of the works delivered.

Finally, it has been confirmed that from the clients' perspective, ORA are used predominantly in the public sector; therefore, it can be claimed that supply-demand relations significantly limit the acceptance ORA in the private sector.

From the client's point of view, drivers clearly prevail over the barriers and therefore, in public procurement, ORA can be used as a strong tool supporting effective use of public resources.

It has been concluded that in situations where public authorities are able to attract a sufficient number of bidders to the tender and also need to ensure transparency in the contractor selection process, use of ORA is the most appropriate and desirable option. The achieved transparency leads also to improved performance of both parties involved. Savings from the purchase prices, together with the time savings have significant potential to contribute to increasing the efficiency of buying institutions.

\section{Acknowledgment}

Financial support enabling the collaboration between Brno University of Technology and University of Ljubljana, received through CEEPUS programme, network no. CIIBG-0022: Teaching and Learning Civil Engineering in European Context is gratefully acknowledged.

The authors would also like to express their gratitude for the support provided by two research projects, namely project Investment in Construction Projects on Ecological Principles financed by Ministry of Education and Science of the Federation of Bosnia and Herzegovina and university project FAST-S-15-2944: Effective Management of Processes in Civil Engineering II.

\section{References}

Abu-El Samen, A., Chakraborty, G., \& Warren, D. (2010). A process-based analysis of e-procurement adoption. Journal of Internet Commerce, 9(3/4), 243-259. http://dx.doi.org/10.1080/15332861.2010.526489

Ali, H. A. E., Al-Sulaihi, I. A., \& Al-Gahtani, K. S. (2013) Indicators for measuring performance of building construction companies in Kingdom of Saudi Arabia. Journal of King Saud University - Engineering Sciences, 25(2), 125-134, http://dx.doi.org/10.1016/j.jksues.2012.03.002

Aloini, D., Dulmin, R., \& Mininno, V. (2012). E-reverse auction design: Critical variables in a B2B context. Business Process Management Journal, 18(2), 219-249. http://dx.doi.org/10.1108/14637151211225180

Bartels, A., Hudson, R., \& Pohlmann, T. (2003). ISM/Forrester Report on Technology in Supply Management: Q3 2003, research paper, Forrester Research Inc.

Bygballe, L. E., \& Ingemansson, M. (2014). The logic of innovation in construction. Industrial Marketing Management, 43(3), 512-524. http://dx.doi.org/doi:10.1016/j.indmarman.2013.12.019

Caniels, M. C. J., \& van Raaij, E. M. (2009). Do all suppliers dislike electronic reverse auctions? Journal of Purchasing and Supply Management, 15(1), pp. 12-23. http://dx.doi.org/10.1016/j.pursup.2008.10.003 
Tomas Hanak, Tomas Chadima, Jana Selih. Implementation of Online Reverse Auctions: Comparison of Czech and...

Charki, M. H., Josserand, E., \& Charki, N. B. (2011). Toward an ethical understanding of the controversial technology of online reverse auctions. Journal of Business Ethics, 98(1), 17-37. http://dx.doi.org/10.1007/s10551-010-0532-z

Carter, C. R., Kaufmann, L., Beall, S., Carter, P. L., Hendrick, T. E., \& Petersen, K. J. (2004). Reverse auctions-grounded theory from the buyer and supplier perspective. Transportation Research Part E: Logistics and Transportation Review, 40(3), pp. 229-254. http://dx.doi.org/10.1016/j.tre.2003.08.004

Cechura, L., \& Mala, Z. (2014). Technology and Efficiency Comparison of Czech and Slovak Processing Companies. Procedia Economics and Finance, 12, 93-102. http://dx.doi.org/10.1016/S2212-5671(14)00324-4

Czech Statistical Office, official web page. https://www.czso.cz/ (accessed April 8, 2015).

Dashnyam, B., Liu, Y., Hsu, P. \& Tsai Y. (2012). Real time prediction of closing price and duration of B2B reverse auctions. Knowledge and Information Systems, 32(3), pp. 697-716. http://dx.doi.org/10.1007/s10115-011-0449-6

Emiliani, M. L. (2000). Business-to-business online auctions: Key issues for purchasing process improvement. Supply Chain Management, 5(4), 176-186. http://dx.doi.org/10.1108/13598540010347299

Emiliani, M. L., \& Stec, D. J. (2002). Realizing savings from online reverse auctions. Supply Chain Management, 7(1), 1223. http://dx.doi.org/10.1108/13598540210414355

Flash Eurobarometer 374. Available from: http://ec.europa.eu/public_opinion/flash/f1_374_en.pdf

Filer, R. K., Jurajda, S., \& Planovsky, J. (1999). Education and wages in the Czech and Slovak Republics during transition. Labour Economics, 6(4), 581-593. http://dx.doi.org/10.1016/S0927-5371(99)00032-9

Foroughi, A., Kocakulah, M., \& Williams, J. (2007). A framework for electronic reverse auction (eRA) research. Journal of Internet Commerce, 6(3), 45-74. http://dx.doi.org/10.1300/J179v06n03_03

Hartley, J. L., Lane, M. D., \& Duplaga, E. A. (2006). Exploring the barriers to the adoption of e-auctions for sourcing. International Journal of Operations and Production Management, 26(2), 202-221. http://dx.doi.org/10. $1108 / 01443570610641675$

Hartley, J. L., Lane, M. D., \& Hong, Y. (2004). An exploration of the adoption of E-auctions in supply management. IEEE Transactions on Engineering Management, 51(2), 153-161. http://dx.doi.org/10.1109/TEM.2004.826010

Hatipkarasulu, Y. \& Gill, J. H. (2004). Identification of Shareholder Ethics and Responsibilities in Online Reverse Auctions for Construction Projects. Science and Engineering Ethics, 10(2), 283-288. http://dx.doi.org/10. 1007/s11948-0040024-6

Hawkins, T. G., Gravier, M. J. \& Wittmann, C. M. (2010). Enhancing reverse auction use theory: An exploratory study. Supply Chain Management, 15(1), pp. 21-42. http://dx.doi.org/10.1108/13598541011018102

Horta, I. M., Camanho, A. S., Moreira da Costa, J. (2012). Performance assessment of construction companies: A study of factors promoting financial soundness and innovation in the industry. International Journal of Production Economics, 137(1), 84-93, http://dx.doi.org/10.1016/j.ijpe.2012.01.015

Jaskowski, P., Sobotka, A., \& Czarnigowska, A. (2014). Decision model for selecting supply sources of road construction aggregates. Engineering Economics, 25(1), 13-20. http://dx.doi.org/10.5755/j01.ee.25.1.3595

Korytarova, J., \& Pospisilova, B. (2015). Evaluation of investment risks in CBA with Monte Carlo method. Acta Universitatis Agriculturae et Silviculturae Mendelianae Brunensis, 63(1), pp. 245-251. http://dx.doi.org/10. 11118/actaun201563010245

Leung, S. W., Mak, S., \& Lee, B. L. P. (2008). Using a real-time integrated communication system to monitor the progress and quality of construction works. Automation in Construction, 17(6), 749-757. http://dx.doi.org/10. 1016/j.autcon.2008.02.003

Liu, Y., Zhong, D., Cui, B., Zhong, G., \& Wei, Y. (2015). Study on real-time construction quality monitoring of storehouse surfaces for RCC dams. Automation in Construction, 49(PA), 100-112. http://dx.doi.org/10.1016/ j.autcon.2014.10.003

Losch, A., \& Lambert, J. S. (2007). Information behaviour in e-reverse auctions: Purchasing in the context of the automobile industry, Journal of Enterprise Information Management, 20(4), 447-464. http://dx.doi.org/10.1108/17 410390710772713

Ministry of Transport, Construction and Regional Development of the Slovak Republic (2015). Rocenka slovenskeho stavebnictva 2015 (Yearbook of the Slovak construction 2015, in Slovak). Bratislava. 93 p.

Nordin, R. M., Takim, R., \& Nawawi, A. H. (2011). Critical Factors Contributing to Corruption in Construction Industry. IEEE Symposium on Business, Engineering and Industrial Applications (ISBEIA), $330-333$. http://dx.doi.org/10.1109/ISBEIA.2011.6088831 
Pearcy, D., Giunipero, L., \& Wilson, A. (2007). A model of relational governance in reverse auctions. Journal of Supply Chain Management, 43(1), 4-15. http://dx.doi.org/10.1111/j.1745-493X.2007.00023.x

Presutti Jr., W. D. (2003). Supply management and e-procurement: Creating value added in the supply chain. Industrial Marketing Management, 32(3), 219-226. http://dx.doi.org/10.1016/S0019-8501(02)00265-1

Purchase, S., \& Dooley, K. (2010). The acceptance and use of e-procurement systems. International Journal of Logistics Research and Applications, 13(6), 459-473. http://dx.doi.org/10.1080/13675561003801063

Ray, A. K., Jenamani, M., \& Mohapatra, P. K. J. (2011). An efficient reverse auction mechanism for limited supplier base. Electronic Commerce Research and Applications, 10(2), 170-182. http://dx.doi.org/10.1016/j.elerap.2009.11.002

Schoenherr, T. \& Mabert, V. A. (2007). Online reverse auctions: Common myths versus evolving reality. Business horizons, 50(5), 373-384. http://dx.doi.org/10.1016/j.bushor.2007.03.003

Smart, A. F. (2010). E-procurement and its impact on supply management - evidence from industrial case studies. International Journal of Logistics Research and Applications, 13(6), 423-440. http://dx.doi.org/10. 1080/13675567.2010.486760

Standing, S., Standing, C., Love, P., \& Gengatharen, D. (2013). How organizing visions influence the adoption and use of reverse auctions. Electronic Commerce Research, 13(4), 493-511. http://doi.org/10.1007/s10660-013-9133-0

Statistical Office of the Slovak Republic, official web page. http://www.statistics.sk/ (accessed April 8, 2015).

Stritesky, M. (2014). New HR Organizational Structures in Czech and Slovak Organizations. Procedia - Social and Behavioral Sciences, 110, 130-139. http://dx.doi.org/10.1016/j.sbspro.2013.12.855

Tarazona-Bermudez, G. M., Pelayo G-Bustelo, B. C., Martinez, O. S., Alvarez, B. T., \& Rojas, L. A. R. (2014). Reverse electronic auction web tool for B2B. Computers in Industry, 65(5), 841-849. http://dx.doi.org/10.1016/j. compind.2013.12.008

Tassabehji, R.Sr. (2010). Understanding e-auction use by procurement professionals: Motivation, attitudes and perceptions. Supply Chain Management, 15(6), 425-437. http://dx.doi.org/10.1108/13598541011080419

The Chartered Institute of Building. (2013). Corruption in the UK construction industry. http://www.ciob.org/ sites/default/files/CIOB\%20research\%20-\%20Corruption\%20in\%20the\%20UK\%20Construction\%20Industry\%20 September\%202013.pdf

Toktas-Palut, P., Baylav, E., Teoman, S., \& Altunbey, M. (2014). The impact of barriers and benefits of e-procurement on its adoption decision: An empirical analysis. International Journal of Production Economics, 158, 77-90. http://dx.doi.org/10.1016/j.ijpe.2014.07.017

Ubeda, R., Alsua, C., \& Carrasco, N. (2015). Purchasing models and organizational performance: A study of key strategic tools. Journal of Business Research, 68(2), 177-188. http://dx.doi.org/10.1016/j.jbusres.2014.09.026

Vitkauskaite, E., \& Gatautis, R. (2008). E-procurement perspectives in construction sector SMEs. Journal of Civil Engineering and Management, 14(4), 287-294. http://dx.doi.org/10.3846/1392-3730.2008.14.28

Wagner, S. M. \& Schwab, A. P. (2004). Setting the stage for successful electronic reverse auctions. Journal of Purchasing and Supply Management, 10(1 spec iss.), pp. 11-26. http://dx.doi.org/10.1016/j.pursup.2003.11.001

Walley, M. J. C., \& Fortin, D. R. (2005) Behavioral outcomes from online auctions: Reserve price, reserve disclosure, and initial bidding influences in the decision process. Journal of Business Research, 58(10), 1409-1418. http://dx.doi.org/10.1016/j.jbusres.2003.10.014

Wang, D., Liu, X., \& Liu, L. (2013). Bid evaluation behaviour in online procurement auctions involving technical and business experts. Electr. Comm. Research and Applications, 12(5), 328-336. http://dx.doi.org/10.1016/ j.elerap.2012.10.001

William, S. P., \& Hardy, C. A. (2007). E-procurement: current issues and future challenges. Proceedings of the European Conference on Information Systems, 12-14 June, Gothenburg, Sweden, 131-142. http://aisel.aisnet.org/ecis2007/133

Yu, Y. W., Lee, C. L. \& Yu, H. C. (2007). B2B online reverse auction: factors that affect the e-procurement performance in Taiwan. Journal of Information and Optimization Sciences, 28(4), 505-521. http://dx.doi.org/10.108 0/02522667.2007.10699757

Zunk, B. M., Marchner, M. J., Uitz, I., Lerch, C., \& Schiele, H. (2014). The role of E-procurement in the Austrian construction industry: Adoption rate, benefits and barriers. International Journal of Industrial Engineering and Management, 5(1), 13-20. http://www.iim.ftn.uns.ac.rs/casopis/volume5/ijiem_vol5_no1_2.pdf

The article has been reviewed.

Received in June, 2015; accepted in June, 2017. 